\title{
Ellipsis
}

2014

\section{Three Recipes}

Ashley N. Hemm

University of New Orleans

Follow this and additional works at: https://scholarworks.uno.edu/ellipsis

Part of the Nonfiction Commons

\section{Recommended Citation}

Hemm, Ashley N. (2014) "Three Recipes," Ellipsis: Vol. 41 , Article 22.

DOI: https://doi.org/10.46428/ejail.41.22

Available at: https://scholarworks.uno.edu/ellipsis/vol41/iss1/22

This Creative Nonfiction is brought to you for free and open access by the Department of English and Foreign Languages at ScholarWorks@UNO. It has been accepted for inclusion in Ellipsis by an authorized editor of ScholarWorks@UNO. For more information, please contact scholarworks@uno.edu. 


\section{Three Recipes}

Ashley Hemm

\section{1) Actually the Last Time Omelet}

- Four eggs (two brown, two green)

- Two slices truffle-infused Brie, chopped fine

- One half small white onion, chopped

- One clove garlic, chopped

- One avocado, sliced

- One Roma tomato, chopped

- One handful pulled pork (miso-ginger marinade)

- Balsamic vinegar to taste

- Herbs de Provence

- Cracked black pepper

- Butter

Sauté onions in butter until they just begin to soften. Add garlic. Add balsamic vinegar. Crack eggs and blend; mix in herbs de Provence and black pepper. Pour egg mixture over onions. Add Brie pieces. When omelet is half-cooked, add tomato, avocado, and pork. Fold omelet over into thirds (if possible). Folding in half is more than acceptable. Top with any remaining tomato and avocado and serve. Pairs well with awkward conversation and the slow, creeping realization that you've made a terrible mistake in not getting out sooner.

Clearly, this dish is a hodgepodge of basic ingredients, leftovers, and items that deserve better treatment than they receive here. Upon reflection, the author understands that this dish occupies a tenuous place between risky and culinary abomination, but the only excuse she can offer is that it seemed like a good idea at the time and that she has since refined her palate substantially. The author contends that the omelet was surprisingly tasty, but that this could be a result of its being the last of its kind. The only thing the author regrets is that it took so long to produce.

\section{2) First Date at My Place Seared Tuna Steaks}

- Two tuna steaks 
- Baby mixed greens

- Candied pecans

- Chow Mein noodles

- Dried cranberries

"Winging It" Marinade:

- Sesame oil

- Soy sauce

- Brown sugar

- Pre-made sesame ginger salad dressing even though you can make the real thing because this is the first time he's coming over and you feel like maybe you shouldn't go all-out just yet

Marinate the tuna steaks in "Winging It" marinade, freshly cracked black pepper, lemon juice, and a pinch of salt for at least a few hours. Toss the baby mixed greens, candied pecans, Chow Mein noodles, and dried cranberries in a very small amount of sesame ginger dressing and arrange on plates. Pour a few tablespoons of olive and sesame oil into a skillet and turn the heat all the way up. Sear tuna to desired temperature and serve atop salads. Garnish with Chow Mein noodles. Open windows and turn on fans to avoid smoke detector if necessary. Pairs well with Pinot noir and the discovery of similar television preferences.

It is perhaps unfair to compare this dish to the Actually the Last Time Omelet, as its level of sophistication and polish is the result of years of testing and refining. This dish says, "I can cook tasty, vaguely healthy meals, but I'm nowhere near as intimidating as your friends who are actual chefs." The mixture of pre-made and fresh ingredients keeps the dish down-to-earth, as does the potential arrival of the fire department depending on one's smoke alarm system. The author would like to note that dried cranberries and candied pecans are entirely optional, but their inclusion may serve as a test of character. She discovered this inadvertently the last time she prepared this dish, as her date ate every last cranberry and pecan despite disliking both the flavor and concept of such accoutrements in a salad.

\section{3) I Guess We're Adults Now Garlic-Encrusted New York Strip}

(Note: recipe works best with two participants)

- Two New York strip steaks, preferably at least 1 " thick

- Olive oil

- Salt and pepper

- One medium-sized onion (Vidalia preferred) 
- One head garlic

- One healthy sprig rosemary

- Skewers

- Grilling implements and accessories (grill, charcoal, lighter fluid, cocktails)

Cover steaks in olive oil, salt, and any preferred seasoning and bring to room temperature. Get the grill ready. Consume cocktails until coals are ready. Chop the onion into large but edible pieces and skewer. Baste with olive oil, salt, and pepper, and grill for about six minutes per side, or until preferred level of char is reached. Set aside. Separate and peel garlic cloves, then skewer. Do not worry about basting. Grill until appropriately soft, about eight to ten minutes. Remove garlic cloves from skewer and mash. Add rosemary, about a tablespoon of olive oil, and salt and pepper to taste. Set aside. Grill steaks for about four minutes, then flip and top with garlic spread. Cover and cook until desired temperature is reached. Serve with onion skewers, a reasonably-priced Cabernet, and the knowledge that you're about to embark upon the double-whammy of a new semester and your impending marriage.

While this recipe is the least complex in terms of ingredients, it requires the most preparation. One can certainly make it alone, but the author recommends against it, as fire, red meat, and cocktails are all better enjoyed with a partner in crime. This dish is less showy than the others, but it's also pretty versatile. One may dress it up by replacing the garlic topping with bleu cheese crumbles or sautéed mushrooms and lump crabmeat, or forego toppings entirely in favor of just enjoying a high-quality meal that doesn't have so many frills because sometimes you just want a nice dinner without having to try so damn hard and isn't the point of this whole thing to just have an enjoyable time without so many expectations? Potatoes are also a nice addition. 